\author{
Мачей Вальчак \\ Силезский университет (Сосновец,, Польша)
}

\title{
СТИЛИСТИЧЕСКАЯ И ЧАСТОТНАЯ СПЕЦИФИКА РУССКИХ И ПОЛЬСКИХ ЛЕКСЕМ С МОРФЕМАМИ БИО-/ВIO-, ГИПЕР-/HIPER-, МЕГA-/MEGA-
}

В предлагаемой статье внимание будет сосредоточено на определении стилистической специфики русских и польских лексем, в морфемной структуре которых присутствуют элементы греческого происхождения биo-/bio-, гипер-/hiper- и мегa-/mega1. Обращение к этим морфемам обусловлено их достаточно высокой в обоих языках частотностью, что констатируется на основании корпусных данных. Помимо этого, выбранным лексемам свойственно постепенное приобретение как морфологической, так и семантической самостоятельности. Отмеченное подтверждается их способностью функционировать вне состава лексемы. Исследовательский материал извлекался из корпусов русского и польского языков (НКРЯ; NKJP). Выбор данных источников дополнительно объясняется тем, что, в отличие от словарей (прежде всего, печатных), они фиксируют языковые единицы в широком текстовом окружении, что неоценимо для выявления различного рода стилистико-семантических тонкостей, особенно с учётом новейших явлений, в том числе и неологического, а точнее, неосемантического характера. Следует отметить, что тексты научного стиля и, следовательно, специальные термины в объект рассмотрения не включались, поскольку им свойственна строго определённая семантика и в то же время стилистическая привязанность, не допускающая возможности их какого-либо варьирования. Необходимо добавить, что вопрос интересующих нас морфем в лингвистике частично уже рассматривался, в частности в работах Е. Калишана (Калишан 1976: 153-160; 1980), однако объектом анализа выступали преимущественно лексемы терминологического характера, которые, как упоминалось выше, не рассматриваются нами.

\footnotetext{
${ }^{1}$ Обсуждаемая проблематика получила более основательное представление в монографии: Вальчак М. (2016), Греческие корни в лексическом составе русского и польского языков (семантический, словообразовательно-морфологический и стилистический аспекты), Katowice.
} 
Стоит подчеркнуть, что одни и те же повторяющиеся в одном примере единицы определялись как одно употребление. Извлечённые из корпусов русского и польского языков, а также из других источников данные позволили составить приводимые далее сопоставительные характеристики слов различных частей речи с избранными морфемами. Каждую таблицу с результатами сравнения предваряет примерный перечень анализируемых лексем вместе с комментарием семантических особенностей избранных единиц. Анализ данных, извлечённых из корпусов, даётся после таблицы.

Объяснения также требует применяемое нами определение изолированная позищия. Под ней подразумевается морфема, фиксируемая обособленно, т.е. не в составе лексемы. Изолированными считались также морфемы, которые, будучи частью сложных слов (напр., биотерроризм), выступали в постпозиции по отношению к анализируемой части речи (ср. продукты $B I O$ ).

Следует также уточнить и объяснить классификацию едниниц, представляющих собой аббревиатуры с наличием соответствующих морфем. Ввиду того, что они выступали преимущественно в качестве наименований различных объектов предпринимательской деятельности - хрематонимов, а точнее эргонимов (см. Kopertowska 2001: 11-33) -, мы решили включить их в группу имён существительных. Все анализируемые единицы приводятся с сохранением правописания оригинала.

Рассматриваемые нами морфемы (корневые био-/bio-, мега-/mega-; аффиксальная гипер-/hiper-) в русских и польских словарных источниках трактуются, в основном, как первые части сложных слов, хотя они постепенно приобретают как семантическую, так и морфологическую самостоятельность: био-/bio- как несклоняемое существительное на -o, а также тяготеющее в сторону несклоняемого прилагательного (ср.: продукты $\mathrm{BIO}$; torba bio), мегa-/mega- и гunep-/hiper- как наречие и прилагательное. Однако в силу того, что два последних фиксируются как самостоятельные лексемы преимущественно в устном варианте разговорной речи, нецелесообразным было бы говорить о регулярном характере данного проявления. Анализ начнём с обсуждения лексических единиц с корнем био-/bio-.

\section{Корень био-/bio-}

Данная морфема, находясь в структуре русских лексем, предполагает их соотнесённость с: 1. жизнью, 2. биологией (Адамчик 2005: 129). Подобная связь обнаруживается у польских лексем, указывая на жизнь, живой организм, жизненный процесс (Bańko 2008: 157). Извлечённые из корпусных ресурсов единицы, особенно в польском языке, проявляют, как представляется, не только отношение к биологии, как научной дисциплине, а также ко всему живому, сколько, скорее всего, указыывают на естественное, химически и технологически не обработанное, натурально полученное и тем самым 
безопасное для человеческого здоровья и окружающей среды экологическое вещество / сырьё / изделие. Особо заметна в случае польского языка частотность данного корня в структуре лексем, относящихся к различным продуктам питания, а также косметики ${ }^{2}$. Отмеченное проиллюстрируем примерами: био-йогурт, био-иампунь; biobar, biojogurt/biogurt, bio ser, bio-żywność, olej bio, produkty bio. Если связь с живым, а точнее с микроорганизмами, как активным ингредиентом вещества, продукта ${ }^{3}$, можно выявить в лексемах био-йогуpm / biogurt / biojogurt, тогда такая связь в случае остальных лексем уже не совсем очевидна и однозначна, поскольку компонент био- в единицах био-шампунь, био-комплекс (удобрение растительного происхождения); biogaz '[...] gaz otrzymywany podczas fermentacji beztlenowej obornika, odpadków organicznych' (Drabik 2011: 115), biopaliwo 'paliwo otrzymywane z roślin' (Drabik 2011: 116), bio ser, bio-żywność, klasa bio, olej bio, produkty bio а также biotatuaz, torba bio (возможно сокращение от torba biodegradowalna), kuracja bio предполагает вероятнее всего растительное, экологическое происхождение (ср. также семаническую близость в данном контексте морфем bio- и eko-, напр., torba bio - ekotorba). Особого комментария требует выявленное словосочетание domowe odpady «bio», в котором посредством данной морфемы указывается на отходы растительного и животного происхождения и био-туалет (также биотуалет) - 'туалет, в котором для утилизации отходов жизнедеятельности человека употребляются только природные материалы' (СЭВ). В остальных выявленных лексемах отчётливо прослеживается соотношение с биологией, напр., био-безопасность (биологическая безопасность), био-оружие (биологическое оружие), био-папа (биологический папа), био-родители (биологические родители), био-терроризм (биологический терроризм); bioróżnorodność (biologiczna różnorodność). Выявленные единицы позволили составить следующие частотно-стилистические характеристики:

русский язык: био-папа, био-родители, био-оружие, био-шампунь, био-туалет, био-комплекс, био-терроризм, био-безопасность, био-йогурт.

польский язык: domowe odpady bio, biojogurt, bio ser, biobar, bioróżnorodność, bioterroryzm, biopaliwo, biotatuaż, torba bio, kuracja bio, olej bio, biogaz, klasa bio, produkty bio, bio-żywność.

2 Многие продукты питания маркируются символом „ВIO”.

${ }^{3} \mathrm{Cp}$. польск. biopreparat - 1. farm. "środek farmaceutyczny zawierający żywe lub martwe drobnoustroje, ich produkty albo ciała odpornościowe otrzymane ze zwierząt uodpornionych na określone choroby'. 2. roln. - 'preparat zawierający zarodniki określonych bakterii chorobotwórczych atakujących niektóre gatunki owadów [...]’ (Bańko 2008: 160). 
Таблица 1. Стилистические особенности русских и польских лексем с корнем био-/bio-

\begin{tabular}{|c|c|c|c|c|c|}
\hline \multicolumn{4}{|c|}{ 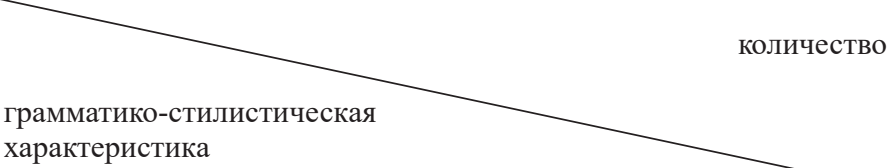 } & русский & польский \\
\hline \multirow{12}{*}{$\begin{array}{l}\text { часть } \\
\text { речи }\end{array}$} & \multirow{3}{*}{ существительное } & \multirow{3}{*}{ стиль } & разговорный & 2 & 2 \\
\hline & & & публицистический & 16 & 5 \\
\hline & & & художественный & 3 & 1 \\
\hline & \multirow{3}{*}{ прилагательное } & \multirow{3}{*}{ стиль } & разговорный & & - \\
\hline & & & публицистический & 6 & - \\
\hline & & & художественный & - & 1 \\
\hline & \multirow{3}{*}{ наречие } & \multirow{3}{*}{ стиль } & разговорный & - & - \\
\hline & & & публицистический & - & - \\
\hline & & & художественный & - & 1 \\
\hline & \multirow{3}{*}{$\begin{array}{l}\text { изолированная } \\
\text { позиция }\end{array}$} & \multirow{3}{*}{ стиль } & разговорный & 6 & 5 \\
\hline & & & публицистический & 11 & 14 \\
\hline & & & художественный & 3 & 3 \\
\hline & & & $\Sigma$ & 47 & 32 \\
\hline
\end{tabular}

На основании приведённых характеристик можно прийти к заключению, что корень био-/bio- в обоих языках проявляет сходную и наибольшую активность в публицистическом стиле (русский - ок. 70\% от общего числа, польский $-55 \%$ ). Менее распространён в разговорном (русский - ок. $17 \%$, польский - ок. 24\%) и художественном стилях (русский - ок. $12 \%$, польский $-17 \%$ ). В польском языке данный корень наиболее частотен в изолированной позиции (польский - 75,8\%, русский - ок. 42,5\%,). Отличительной чертой русского языка следует считать бо́льшую частотность существительных (русский $-44,6 \%$, польский $-17,2 \%$ ) и прилагательных (русский - 12,7\%, польский - 3,125\%), особенно в публицистическом стиле. В русском материале зафиксировано и большее число существительных в художественных текстах. Что касается наречий, в их составе в русском материале данный корень не обнаружен, в польском встретился только один пример, что не следует считать показательным отличием между обоими языками. 


\section{Корень мега-/mega- ${ }^{4}$}

Данный корень в обоих языках является первой частью сложных слов со смежным значением:

польск. mega- 'tworzy 1. od jednostek miary nazwy jednostek milion razy większych, np. megaherc, megawat, megabajt'.

2. 'od rzeczowników rzeczowniki wskazujące na znaczne rozmiary czegoś, np. megamarket, megakoncert' (Bańko 2017: 839);

рус. мега... ${ }^{1}$

1. 'Начальная часть сложных слов, вносящая значение: в метрической системе мер - миллион или в миллион раз больше (мегаватт, мегаграмм, мегакалория $[\ldots])^{\prime}$, мега...

2. Начальная часть сложных слов, вносящая значение: имеющий огромные размеры (мегалит, мегаспора [...]) (Ефремова 2005: 45).

Следует отметить, что в русском языке прослеживается омонимизация данной морфемы, в то время как в польском полисемантизация. Кроме того, в словарных источниках не отмечается их постепенная, особенно в разговорном языке, адъективация и адвербиализация, и в этой связи приобретение новой грамматической функции как средства образования безотносительной превосходной степени сравнения (мега редкий = очень редкий; mega modny = bardzo modny) вплоть до достижения эффекта тавтологизации (мега гигантский, мега крупный, где гигантский, крупный = очень большой). Примечательно, что в подавляющем большинстве выявленных единиц компонент мегa-/mega- дополнительно привносит элемент положительной оценки, в силу чего в лингвистике определяется иногда как показатель «одобрения» (Рacuła 2011: 33). Кроме того, особенно в польском языке, наблюдается способность данного компонента заменять прилагательные типа отличный, превосходный, классный / wspaniaty, świetny, cudowny и т.п. (ср. мега плеер, мега бонусы; mega pianinko, mega pościel). В таблице ниже приводятся стилистические и частотные характеристики выявленных частей речи, предваряясь перечнем примерных единиц.

русский язык: мега классная, мега стильный, мега мощный, мега-мягкая, мега-модный, мега красивый, мега нарядный, мега огромный, мега гламурный, мега редкий, мега распродажа, мега-карандаш, мега комплект, мега сборник, мега пакет, мега коллекиия, мега табличка, мега плеер, мега-ботинки, мега-лот, мега DVD рекордер, мегавещуь, мега бонусы, мега гигантский, мега крупное кольияо.

4 Учитывая то обстоятельство, что большинство словарей иностранных слов и толковых фиксируют данную морфему как первую часть сложных слов, а также постепенное приобретение ею всё большей лексико-семантической и морфологической самостоятельности, особенно вне состава терминологических единиц, мы решили отнести её в группу корневых. 
польский язык: mega gratis, mega jenot, mega parametry, mega pianinko, mega pościel, mega prezent, sexi mega biodrówki, mega biust, mega bluza, mega energia, mega kolczyki, mega masa, mega moc, mega produkcja, mega promocja, mega przyrost, mega rozmiar, mega siła, mega teczka, mega wybór, mega wyprzedaż, mega zasięg, mega zestaw, mega loteria, mega duża, mega dużo, mega bezpieczny, mega tanio, mega wygodny, mega mocna, mega gruby, mega cieply, mega niska, mega wytrzymaty, mega wygodne, mega modny, mega fajny, mega szybki / megaszybki, mega sexowny, mega sexy sexi.

Таблица 2. Стилистические особенности русских и польских лексем с корнем мега-/mega-

\begin{tabular}{|c|c|c|c|c|c|}
\hline \multicolumn{4}{|c|}{$\begin{array}{l}\text { грамматико-стилистическая } \\
\text { характеристика }\end{array}$} & \multirow{2}{*}{$\begin{array}{c}\text { русский } \\
24\end{array}$} & \multirow{2}{*}{$\begin{array}{c}\text { польский } \\
50\end{array}$} \\
\hline \multirow{15}{*}{$\begin{array}{l}\text { часть } \\
\text { речи }\end{array}$} & \multirow{3}{*}{ существительное } & \multirow{3}{*}{ стиль } & разговорный & & \\
\hline & & & публицистический & 18 & 12 \\
\hline & & & художественный & 1 & 3 \\
\hline & \multirow{3}{*}{ прилагательное } & \multirow{3}{*}{ стиль } & разговорный & 18 & 31 \\
\hline & & & публицистический & - & - \\
\hline & & & художественный & - & - \\
\hline & \multirow{3}{*}{ наречие } & \multirow{3}{*}{ стиль } & разговорный & - & 6 \\
\hline & & & публицистический & - & - \\
\hline & & & книжный & - & - \\
\hline & \multirow{3}{*}{ глагол } & \multirow{3}{*}{ стиль } & разговорный & - & 3 \\
\hline & & & публицистический & - & - \\
\hline & & & книжный & - & - \\
\hline & \multirow{3}{*}{$\begin{array}{l}\text { изолированная } \\
\text { позиция }\end{array}$} & \multirow{3}{*}{ стиль } & разговорный & - & 15 \\
\hline & & & публицистический & 4 & 6 \\
\hline & & & художественный & 1 & 1 \\
\hline & & & $\Sigma$ & 67 & 127 \\
\hline
\end{tabular}

Полученные данные свидетельствуют о том, что особенную активность корень мега-/mega- проявляет в составе существительных (ок $39 \%$ от общего числа) и прилагательных (ок. 24\%) в разговорном и публицистическом стилях. Польскому языку свойственна также высокая частотность изолированных употреблений, что характерно и для указанных стилей. В русском языке появляется некоторое затруднение в однозначной интерпретации изолированного употребления, что, вероятно, дополнительно может быть связа- 


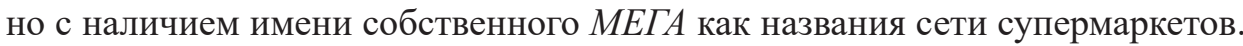
В подавляющем большинстве обнаруженные единицы представляют собой в обоих языках лексемы нейтральные (pościel, wyprzedaż, prezent, kolczyki и т.д., комплект, карандаш, сборник); появляются, однако, и слова, маркированные посредством соответствующих словообразовательных процедур: 1. суффиксации: суффиксы субъективной оценки, особенно в польском материале (cieplutki, mięciutki, pianinko; табличка); 2. обратной деривации (пак; paka, lala). В русском языке, в отличие от польского, слов стилистически маркированных выявлено больше (разг. классныли, гламурный, прикол). В несколько большем количестве русских примеров мега- выступает как начальный компонент собственных существительных, напр., МегаЯлта, МегаОйл, Мега-Авто, Мега-Строй. Полученные результаты указывают на бо́льшую активность данного корня в польском языке.

\section{Префикс гипер-/hiper-}

Польские словарные источники последовательно фиксируют данную морфему как часть сложных слов: польск. hiper- 'pierwszy człon wyrazów złożonych wskazujących na nadmiar lub ponadwymiarowość czegoś, np. hipertrofia, hipermedia (Drabik 2011: 358; Bańko 2008: 499; Kopaliński 1994: 211). В русскоязычных источниках она трактуется и как часть сложных слов, и как приставка: „Первая составная часть сложных слов или приставка, указывающая на превышение нормы” (Окунцова 2009: 93; Адамчик 2005: 223). Поскольку в данном исследовании однозначное определение и теоретическое решение вопроса аффиксального либо корневого характера морфемы zunep-/hiper- не является основной целью, для порядка относим её к приставкам, отталкиваясь от диахронических представлений и учитывая первоначальный (префиксальный) её характер в греческом языке. Тем не менее, с точки зрения совремменного состояния русского и польского языков, как отмечалось ранее, наблюдается постепенное сближение её функций с упоминаемым выше компонентом мега-/mega-, что проявляется преимущественно в способности выступать в качестве наречия и показателя безотносительной превосходной степени (ср. гипер-удовольствие = огромнейшее удовольствие; hiper tanio, hiper wygodny = bardzo, niezwykle tanio, wygodny), а также прилагательного со значением положительной оценки (гипер сборник = отличный, замечательный сборник; hiper pilotki = wspaniałe, świetne pilotki). Надо заметить, что среди русских единиц встречаются и лексемы, в которых гипер- предполагает чрезмерность, превышение нормы, напр. гипер-оптимизм, гипер-чеченизация, гиперинтеллектуал. Как представляется, в случае морфем мега- и гипер- (а также супер-) есть основания говорить об их возрастающем градуальном друг к другу отношении. Отмеченная возрастающая градуальность, нередко обусловленная контекстом, заключается в том, что компонент мега-/mega- предполагает высокую степень или интен- 
сивность признака, в то время как морфема гunep-/hiper- предельную степень или интенсивность, напр. mega gustowny vs hiper gustowny, mega dokładny modut GPS vs hiper dokładny modut GPS. В приведённых контекстах значение возрастающей интенсивности качества легко ощущается, не ассоциируясь при этом с какой-либо чрезмерной, превышающей норму степенью проявления признака. Хорошей иллюстрацией может также послужить пара лексем супермаркет - гипермаркет, в которой именуемые ими объекты противопоставляются по своему размеру (занимаемой площади): супермаркет 'мага-

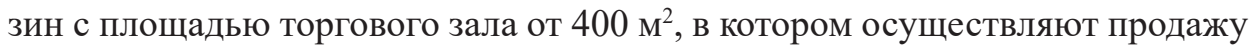
продовольственных и непродовольственных товаров повседневного спроса преимущественно по методу самообслуживания (СФиЮТ) - гипермаркет 'магазин с площадью торгового зала от 5000 м², в котором осуществляют продажу продовольственных и непродовольственных товаров универсального ассортимента преимущественно по методу самообслуживания' (СФиЮТ). Лексемы с данной морфемой обладают следующими частеречно-стилистическими характеристиками:

русские: гипер-сборник / гипер сборник, гипер-раритет, гипер блондусилитель, гипер-чеченизация, гипер-держава, гипер-сочреализм, гипер-универсальность, гипер-оптимизм, гиперинтеллектуал, гипер-удовольствие.

польские: hiper tendencyjne trampki, hiper tanio, hiper wygodne kozaczki, hiper cienka $i$ wytrzymała podkładka pod mysz, hiper jasny, hiper wzmocniony, hiper dokładny modut GPS, hiper zestaw, potężny hiper reflektor, hiper termin, hiper btysk, hiper gustowny, hiper unikat, hiper pilotki; hiper perfumowa promocja, hiper-pojemny pojemnik, hipermarket.

Таблица 3. Стилистические особенности русских и польских лексем с префиксом zunep-/hiper-

\begin{tabular}{|c|c|c|c|c|c|}
\hline \multicolumn{4}{|c|}{$\begin{array}{l}\text { грамматико-стилистическая } \\
\text { характеристика }\end{array}$} & русский & польский \\
\hline \multirow{6}{*}{$\begin{array}{l}\text { часть } \\
\text { речи }\end{array}$} & \multirow{3}{*}{ существительное } & \multirow{3}{*}{ стиль } & разговорный & 4 & 8 \\
\hline & & & публицистический & 6 & 3 \\
\hline & & & художественный & - & - \\
\hline & \multirow{3}{*}{ прилагательное } & \multirow{3}{*}{ стиль } & разговорный & - & 8 \\
\hline & & & публицистический & - & 2 \\
\hline & & & художественный & - & - \\
\hline
\end{tabular}




\begin{tabular}{|c|c|c|c|c|c|}
\hline \multicolumn{4}{|c|}{$\begin{array}{l}\text { грамматико-стилистическая } \\
\text { характеристика }\end{array}$} & \multirow{2}{*}{$\begin{array}{c}\text { русский } \\
\text { - }\end{array}$} & \multirow{2}{*}{$\begin{array}{c}\text { польский } \\
1\end{array}$} \\
\hline \multirow{6}{*}{$\begin{array}{l}\text { часть } \\
\text { речи }\end{array}$} & \multirow{3}{*}{ наречие } & \multirow{3}{*}{ стиль } & разговорный & & \\
\hline & & & публицистический & - & - \\
\hline & & & художественный & - & - \\
\hline & \multirow{3}{*}{$\begin{array}{l}\text { изолированная } \\
\text { позиция }\end{array}$} & \multirow{3}{*}{ стиль } & разговорный & - & 3 \\
\hline & & & публицистический & - & 4 \\
\hline & & & художественный & - & 3 \\
\hline & & & $\Sigma$ & 10 & 32 \\
\hline
\end{tabular}

На основе приведённых единиц можно увидеть, что в обоих языках, в частности, в русском, образования с данным префиксом не частотны. Преимущественно они обнаруживаются в составе существительных (особенно в русской части материала) и польских прилагательных (в русском не были обнаружены). В польском материале наблюдается регулярное распространение лексем с данной морфемой в составе существительных $(34,4 \%)$, в изолированной позиции (34,4\%), и прилагательных (31,3\%). В составе наречий элемент встречается крайне редко $(3,1 \%)$. С точки зрения стилистических показателей, польские лексемы особенно активны в разговорном языке $(62,5 \%)$, менее распространены в публицистике $(28,13 \%)$ и художественных текстах (9,4\%). Русские лексемы, в свою очередь, частотны в публицистике $(60 \%)$, менее активны в разговорной речи (40\%).

Проведённый анализ позволяет обнаружить свойственную польскому языку бо́льшую стилистическую маркированность и, тем самым, более значительное число дериватов с рассматриваемыми морфемами. Оба языка совпадают с точки зрения немалой частотности дериватов, в структуре которых присутствует корень мега-/mega, а также высокой частотности лексем с анализируемыми компонентами в разговорном и публицистическом стилях. Отмеченные особенности не удивляют, поскольку, как можно полагать, именно публицистические тексты (также рекламные) являются наиболее доступными, будучи предназначены для широкого круга получателей.

\section{Библиография}

Адамчик В. В. (2005) (ред.), Новейший словарь иностранных слов и выражений, Минск.

Вальчак М. (2016), Греческие корни в лексическом составе русского и польского языков (семантический, словообразовательно-морфологический и стилистический аспекты), Katowice. 
Ефремова Т. Ф. (2005), Современный толковый словарь русского языка, том II, Москва.

Калишан Е. (1976), Препозитивные блоки греко-латинского происхождения как словообразовательные элементы в русском и польском языках, „Studia Rossica Posnaniensia” nr 8, c. $153-160$.

Калишан Е. (1980), Интернациональные препозитивные морфемы греко-латинского происхождения в современном русском и польском словообразовании, Poznań.

НКРЯ: Национальный корпус русского языка, http://www.ruscorpora.ru/.

Окунцова Е. А. (2009) (сост.), Новейший словарь иностранных слов, Москва.

СФиЮТ: Словарь финансовых и юридических терминов, https://www.consultant.ru/law/ref/ ju_dict/

СЭВ: Свободная эничилопедия Википедия, https://ru.wikipedia.org/wiki/Биотуалет.

Bańko M. (2008) (red.), Wielki słownik wyrazów obcych, Warszawa.

Bańko M. (2017) (red. nauk.), Inny słownik języka polskiego PWN, tom 1, Warszawa.

Drabik L. (2011) (oprac.), Stownik wyrazów obcych. Z przykładami i poradami, Warszawa.

Kopaliński W. (1994), Stownik wyrazów obcych i zwrotów obcojęzycznych. Z almanachem, Warszawa.

Kopertowska D. (2001), Struktura współczesnych chrematonimów na tle dawnego nazewnictwa tego zakresu, [w:] red. Ł. M. Szewczyk, M. Czachorowska, Język polski w rozwoju, Bydgoszcz, s. 11-33.

NKJP: Narodowy Korpus Języka Polskiego, http://nkjp.p1/.

Pacuła J. (2011), Leksykalne wykładniki aprobaty we współczesnej polszczyźnie potocznej. Źródła - ewolucja - prognozy, „Kwartalnik Językoznawczy” nr 2 (6), s. 32-49, http://www.kwartjez. amu.edu.p1/teksty/teksty2011_2_6/Pacula.pdf.

\section{THE STYLISTIC AND FREQUENCY SPECIFICITY \\ OF THE POLISH AND RUSSIAN LEXEMS WITH \\ THE БИO-/BIO-, ГИПЕP-/HIPER-, MEГA-/MEGA- MORPHEMS}

(Summary)

The paper presents the analysis of the selected Russian and Polish lexems containing the Greek root morphems био-/bio-, мега-/mega- and the prefix morphem zunep-/hiper- from the point of view of their stylistic and frequency properties in the Russian and Polish parts of speech. The material was drawn mainly from the National Corpus of the Polish Language (Narodowy Korpus Języka Polskiego) and the National Corpus of the Russian Language (Национальный корпус русского языка). This material and the data from the foreign words dictionaries as well as from the explanatory dictionaries were searched with the regard to all functional styles except the scientific one due to its specificity which allows no stylistic and semantic variantivity.

The high frequency of the Russian and Polish lexems containing the above morphems in the colloquial and columnist style makes it possible to assume that the feature texts as well as promotional ones are widely available for the vast groups of audience. Thus feature and and columnist texts are the main channel of those lexems' linguistic distribution.

Keywords: morphemes био-/bio-, мега-/mega-, гипер-/hiper, functional styles, frequency, semantics 


\section{STYLISTYCZNA I FREKWENCYJNA SPECYFIKA ROSYJSKICH I POLSKICH LEKSEMÓW Z MORFEMAMI БИО-/ВIO-, ГИПЕР-/HIPER-, MEГA-/MEGA-}

(Streszczenie)

W niniejszym artykule omówiono wybrane rosyjskie i polskie leksemy zawierające morfemy greckiego pochodzenia био-/bio-, мега-/mega- oraz zипер-/hiper- z punktu widzenia ich właściwości stylistycznych i frekwencyjnych. Materiał badawczy został zaczerpnięty głównie z narodowych korpusów językowych oraz słowników wyrazów obcych i objaśniających. Pod uwagę wzięto wszystkie style funkcjonalne języka rosyjskiego i polskiego z wyjątkiem naukowego, który ze względu na swoją specyfikę i precyzję semantyczną należących doń terminów nie pozwala na jakąkolwiek znaczeniową wariantywność badanych leksemów.

Słowa kluczowe: morfemy био-/bio-, мега-/mеga-, гипер-/hiper, style funkcjonalne, frekwencja, semantyka 